\title{
Health Literate Healthcare Organizations and their Role in Future Healthcare
}

Sibel Altin ${ }^{1^{*}}$ and Stephanie Stock ${ }^{1}$

${ }^{1}$ Institute for Health Economics and Clinical Epidemiology, University Hospital of Cologne, Köln, Germany

*Corresponding author: Sibel Altin,Institute for Health Economics and Clinical Epidemiology, University Hospital of Cologne, Köln, Gleueler Str. 176-178, 50935 Köln, Germany; Tel: 0221 - 4679 -120; E-mail: sibel.altin@uk-koeln.de

Received date: Feb 17, 2014, Accepted date: Mar 11, 2015, Published date: Mar 18, 2015

Copyright: ( 2015 Altin S et al. This is an open-access article distributed under the terms of the Creative Commons Attribution License, which permits unrestricted use, distribution, and reproduction in any medium, provided the original author and source are credited.

\begin{abstract}
There is a growing need for a system change towards more patient-centred and health literate healthcare systems. One valuable approach for change on the system-level is the redesign of health organizations to health literate healthcare organizations (HLHO). This process requires sufficient efforts in teamwork, committed leadership and outcome monitoring. Nurses could make major contributions to the overall system change by integrating their expertise in the redesign of health care organizations in health literate ones.
\end{abstract}

Keywords: Health literacy; Nursing; Health literate healthcare organizations; Patient-centred care

\section{Relevance of System Redesign for Public Health and Population Health Outcomes}

Nowadays, most healthcare systems face a rapid transformation of care processes and structures due to fast-moving technological developments in the fields of medical research and health information technology leading to advances in healthcare coverage and delivery system design [1]. These changes constantly increase the complexity of healthcare systems demanding more patient engagement and broader patient capacities to navigate through healthcare systems $[2,3]$. To achieve the latter, patients need much more health literacy skills such as to access and understand health information, interact with health professionals and apply health information to make appropriate health decisions [4]. Unfortunately, many patients are not sufficiently equipped with competencies that are vital to health literacy. They experience difficulties when reading, writing and communicating efficiently as well as understanding numbers [5]. As a consequence, patients feel challenged to use health information in a way that they can navigate the healthcare system better $[1,6]$. Thus, increasing body of research demonstrates that limited health literacy affects large parts of the US and European population and ultimately contributes to undesirable outcomes including limited ability to take medication appropriately and manage own health, more hospitalizations and greater use of emergency care $[5,7,8]$. As a consequence, the Institute of Medicine as well as the US Department of Health and Human Services propose to address the challenges of limited health literacy by transforming healthcare systems to more health literate ones by integrating elements of patient-centred care and health literacy into processes and structures of healthcare organizations $[9,10]$. In order to be health literate, healthcare organizations need to implement structures that ensure that patients understand relevant health information and are capable to act upon these information in order to make thorough health decisions. The approach of health literate healthcare organizations (HLHO) receives considerable support from healthcare stakeholders and policy makers around the world arguing that patients have the right to receive health information that helps them make informed choices [11,12]. For them, system change towards increasing patient safety, healthcare quality and equity can only be achieved by implementing Health Literate Healthcare Organizations (HLHO) and putting the patient and his informational needs and preferences first [1].

\section{What is a Health Literate Healthcare Organization and why does it Matter?}

Since health literacy is the product of individual capabilities and the health literacy related demands emerging from the complexity of healthcare systems, HLHO represent a valuable way to align healthcare demands better with patients and public skills and capacities $[13,14]$. In this regard, a HLHO supports patients to navigate, understand, and use information and services to take care of their health [11]. It is denoted as an organization that enables patients to read and comprehend instructions, adhere to directions of health professionals, seek care early when required, recognize warning signs and ask questions whenever needed. According to the Institute of Medicine there are ten attributes that characterize a health literate healthcare organization as presented in Table 1 [11]. These characteristics include the implementation and monitoring of an organizational mission, operations and interventions that put aspects of health literacy in the centre of the organizational culture, the delivery of easy to understand written and oral health information as well as the provision of patientcentred communication strategies. Since the different health professions (e.g. physicians, nurses, pharmacists in in- and outpatient care settings) in a healthcare organization are operating as change agents and guiding the redesign of processes and structures towards a HLHO, it is of major importance to put these in the centre of the change process by assigning them specific work profiles and agentroles [12]. So far, research on HLHO reveals that certain health literacy interventions used in the clinical context do have an impact on patient outcomes. In this regard, there is evidence that communication training for health professionals enhances patient understanding, reduces medicine-taking errors and increases cancer screening rates [15-17]. An intervention in the coordination of care reveals that a reengineered discharge process including patient education and better organized hospital transition reduces hospitalization rates by thirty percent [18]. These findings demonstrate that the organizational 
approach to focus more on the informational needs of patients is a

valuable strategy to improve patient outcomes and healthcare quality.

\begin{tabular}{|c|c|c|}
\hline No. & Attributes of a health literate health organization & Examples of nurse role \\
\hline 1 & $\begin{array}{l}\text { Has leadership that makes health literacy integral to it's mission, structure } \\
\text { and operations }\end{array}$ & $\begin{array}{l}\text { - Serves as a multiplier for health literacy messages and actions } \\
\text { - Supports organizational redesign } \\
\text { - } \quad \text { Joins the health literacy task force in her/his organization }\end{array}$ \\
\hline 2 & $\begin{array}{l}\text { Integrates health literacy into planning, evaluation measures, patient safety } \\
\text { and quality improvement }\end{array}$ & $\begin{array}{l}\text { - Conducts health literacy assessments among patients and the workforce for } \\
\text { the development of organizational strategies } \\
\text { - Conducts evaluations of organizational health literacy interventions to } \\
\text { develop benchmarks for patient safety and service quality }\end{array}$ \\
\hline 3 & Prepares the workforce to be health literate and monitors programs & $\begin{array}{l}\text { - } \quad \text { Participates in health literacy training programs } \\
\text { - } \quad \text { Organizes peer to peer training in health literacy skills }\end{array}$ \\
\hline 4 & $\begin{array}{l}\text { Includes populations served in the design, implementation and evaluation } \\
\text { of health information and services }\end{array}$ & $\begin{array}{l}\text { - Helps to identify individuals with limited health literacy } \\
\text { - } \quad \text { Seeks feedback on the quality of provided information }\end{array}$ \\
\hline 5 & $\begin{array}{l}\text { Meets needs of populations with a range of health literacy skills while } \\
\text { avoiding stigmatization }\end{array}$ & $\begin{array}{l}\text { - Helps finding out the informational needs of patients with limited health } \\
\text { literacy } \\
\text { - Offers services to help patients with limited health literacy to navigate } \\
\text { through the organization }\end{array}$ \\
\hline 6 & $\begin{array}{l}\text { Uses health literacy strategies in interpersonal communication an confirms } \\
\text { understanding at all points of contact }\end{array}$ & $\begin{array}{l}\text { - Confirms understanding when communicating with patient (e.g. teach-back } \\
\text { method) } \\
\text { - Secures language assistance for patients with foreign languages }\end{array}$ \\
\hline 7 & $\begin{array}{l}\text { Provides any access to health information and services and navigation } \\
\text { assistance }\end{array}$ & $\begin{array}{l}\text { - Provides access to information and ensures that all informational needs are } \\
\text { met } \\
\text { - Performs navigation services by scheduling appointments for service } \\
\text { providers needed in the care trajectory }\end{array}$ \\
\hline 8 & $\begin{array}{l}\text { Designs and distributes print, audio/visual materials, and social media } \\
\text { content that is easy to understand and act on }\end{array}$ & $\begin{array}{l}\text { - Provides access to print, audio/visual health materials and social media } \\
\text { content for patients with limited health literacy skills }\end{array}$ \\
\hline 9 & $\begin{array}{l}\text { Addresses health literacy in high-risk situations, including care transitions } \\
\text { and communications about medicine }\end{array}$ & $\begin{array}{l}\text { - Identifies high risk situations/topics for patients with limited health literacy } \\
\text { skills and addresses these situations/topics by using clear communication } \\
\text { and offering information }\end{array}$ \\
\hline 10 & $\begin{array}{l}\text { Communicates clearly what health plans cover and what individuals will } \\
\text { have to pay for services }\end{array}$ & $\begin{array}{l}\text { - Provides easy to understand information on health insurance policies } \\
\text { regarding the health services needed } \\
\text { - Communicates out-of-pocket payments required for the services needed }\end{array}$ \\
\hline
\end{tabular}

Table 1: Nurses role in a Health Literate Healthcare Organization, by attribute

\section{How can Healthcare Organizations be Redesigned and what Role do Nurses Play?}

To become health literate, organizations need to undergo an organizational self-assessment to identify health literacy-based barriers and facilitators [11]. After that, organizations can start to address the attributes of a HLHO by focusing on organizational structures and the qualification of the workforce. They can start training their staff in clear communication techniques, in securing language assistance for speakers of foreign languages, and providing needed assistance to patients without stigmatizing them. Further, they can design and distribute written/audio/visual health information tailored to the differing health literacy levels and needs of patients. In addition, they can plan and implement monitoring systems that continuously identify patient's health literacy needs and the effectiveness of implemented health literacy interventions from the patient perspective by using already available assessment tools [11]. In this process, especially nurses who are at the forefront of educating patients and serve as vocal advocates for vulnerable groups play a pivotal role in taking over certain responsibilities as change agents [19-21]. As depicted in Table 1, there are several tasks nurses can perform to support organizational change to a HLHO. First of all, they can serve as multipliers of the overall vision and strategy and support the organization in developing, implementing, monitoring and evaluating health literacy interventions. Further, they can participate in training programs for communication and information brokerage, use the knowledge gained in routine care and training of other peers.

Recently, there are sophisticated concepts and tools in place that are appropriate to initiate system-level changes in healthcare organizations. Nurses should be encouraged to participate in the implementation of concepts such as the "Health Literacy Universal Precautions". The concept aims to enable health professionals to approach all patients who are likely to be at risk of not understanding information relevant to improving their own health. According to the universal precautions approach, HLHO need standard procedures for clear and actionable information and communication and easy to understand patient education materials [22]. The Health Literacy Universal Precautions Toolkit recently developed by the AHRQ serves as a guideline for the step-by-step implementation of interventions integrating health literacy elements into the health care organization 
[23]. It includes interventions on clear provider communication (e.g. teach-back method), interventions on information brokerage (e.g. design and distribution of easy to read/understand health information/ education materials) as well as interventions on care coordination and self-management support such as the application of patient follow-up, medication review, action plans and appointment scheduling. Nurses could play a pivotal role in the implementation and evaluation of the interventions recommended in the toolkit and could serve as leaders of organizational change. Already existing evidence reveals that the integration of nurses in health literacy interventions yields promising results $[24,25]$. Future research should evaluate the effectiveness of recommended low health literacy strategies in health organizations, identify best practices, and determine how different health professions might contribute best to organizational change.

\section{References}

1. Koh HK, Berwick DM, Clancy CM, Baur C, Brach C, et al. (2012) New federal policy initiatives to boost health literacy can help the nation move beyond the cycle of costly 'crisis care'. Health Aff (Millwood) 31: 434-443.

2. Rudd RE (2005) Literacy demands in health care settings: The patient perspective., in Understanding health literacy: Implications for medicine and public health., Schwartzberg JG, Van Geest JB, Wang CC, AMA Press: Chicago.

3. Bergeson SC, Dean JD (2006) A systems approach to patient-centered care. JAMA 296: 2848-2851.

4. Rudd RE, Anderson JE (2006) The health literacy environement of hospitals and health centers. National Center for the Study of Adult Learning and Literacy.

5. ODPHP (2008) America's health literacy: Why we need accessible health information. U.S. Department of Health and Human Services.

6. Koh HK, Brach C, Harris LM, Parchman ML (2013) A proposed 'health literate care model' would constitute a systems approach to improving patients' engagement in care. Health Aff (Millwood) 32: 357-367.

7. Berkman ND, Sheridan SL, Donahue KE, Halpern DJ, Crotty K (2011) Low health literacy and health outcomes: an updated systematic review. Ann Intern Med 155: 97-107.

8. http://www.health-literacy.eu

9. Høstgaard AM (2006) Change readiness research. A qualitative study of variations in participation. Stud Health Technol Inform 124: 705-710.

10. IOM (2004) Health literacy: A prescription to end confusion. Washington D.C. The National Academy Press.
11. http://iom.edu/ /media/Files/Perspectives-Files/2012/DiscussionPapers/BPH_Ten_HLit_Attributes.pdf

12. Brach C, Dreyer BP, Schillinger D (2014) Physicians' roles in creating health literate organizations: a call to action. J Gen Intern Med 29: 273-275.

13. Parker RM (2009) What? So what? Now what? in Measures of Health Literacy: Workshop Summary, I.o.M. (US), Editor. National Academies Press: Washington DC.

14. Rudd RE (2003) Improvement of health literacy, in Communicating health: Priorities and strategies for progress. U.S. Department of Health and Human Services: Washington DC.

15. Ferreira MR (2005) Health care provider-directed intervention to increase colorectal cancer screening among veterans: results of a randomized controlled trial. J Clin Oncol, $23: 15$

16. Wolf MS, Davis TC, Curtis LM, Webb JA, Bailey SC, et al. (2011) Effect of standardized, patient-centered label instructions to improve comprehension of prescription drug use. Med Care 49: 96-100.

17. Campbell FA (2004) The effect of format modifications and reading comprehension on recall of informed consent information by lowincome parents: a comparison of print, video, and computer-based presentations. Patient Educ Couns, 53: 205-16.

18. Jack BW, Chetty VK, Anthony D, Greenwald JL, Sanchez GM, et al. (2009) A reengineered hospital discharge program to decrease rehospitalization: a randomized trial. Ann Intern Med 150: 178-187.

19. Murphy-Knoll L (2007) Low health literacy puts patients at risk: the Joint Commission proposes solutions to national problem. J Nurs Care Qual 22: 205-209.

20. Mancuso JM (2009) Assessment and measurement of health literacy: an integrative review of the literature. Nurs Health Sci, 11: 77-89.

21. Pignone M (2005) Nurse Practitioners' Knowledge, Experience, and Intention to Use Health Literacy Strategies in Clinical Practice. Journal of General Internal Medicine, 20: 185-192.

22. http://www.ahrq.gov/professionals/quality-patient-safety/qualityresources/tools/literacy-toolkit/healthliteracytoolkit.pdf

23. http://www.ahrq.gov/professionals/quality-patient-safety/qualityresources/tools/literacy-toolkit/

24. Dennis S, Williams A, Taggart J, Newall A, Denney-Wilson E et al. (2012) Which providers can bridge the health literacy gap in lifestyle risk factor modification education: a systematic review and narrative synthesis. BMC Fam Pract 13: 44.

25. French KS (2015) Transforming Nursing Care Through Health Literacy ACTS. Nurs Clin North Am 50: 87-98. 